\title{
El secreto profesional médico y las personas con discapacidad, en el ordenamiento jurídico colombiano*
}

\author{
The Professional Medical Secret and the Persons with Disability, \\ in the Juridical Colombian Classification \\ O segredo profissional médico e as pessoas com deficiência, no \\ ordenamento jurídico colombiano
}

\author{
Sebastian Portilla Parra ${ }^{* *}$
}

FECHA DE RECEPCIÓN: 23 DE ENERO DE 2019. FECHA DE APROBACIÓN: 2 DE MARZO de 2019

Doi: http://dx.doi.org/10.12804/revistas.urosario.edu.co/sociojuridicos/a.7591

Para citar este artículo: Portilla Parra, S. (2019). El secreto profesional médico y las personas con discapacidad, en el ordenamiento jurídico colombiano. Revista Socio-Jurídico 21(2), 357-386. Doi: http://dx.doi.org/10.12804/revistas. urosario.edu.co/sociojuridicos/a.7591

\section{RESUMEN}

El secreto profesional médico constituye garantía constitucional de imperioso cumplimiento para el idóneo desarrollo de las ciencias de la salud y para la prevalencia de determinados derechos fundamentales, inherentes a toda persona. Representa un deber que el galeno (entiéndase, todo personal sanitario) debe cumplir invariablemente, evitando que la información que conociere en razón de su profesión sea divulgada a terceros, salvo excepciones legales. Sin embargo, en el caso concreto de las personas con discapacidad lo anterior se complica, pues por la exigua implementación del modelo social, es recurrente la figura del tutor o tercero habilitado para tomar decisiones a nombre del paciente, lo que discrepa con el carácter personalísimo de aquella figura que permite la relación de confidencialidad inescindible entre galeno-paciente; en suma, posee doctrina y legislación precaria. Este texto pretende reafirmar la vigencia y salvaguarda del secreto profesional en cuanto a los pacientes con discapacidad, permitiendo una relación bilateral con el galeno,

* Artículo inédito, resultado de la actividad investigativa del autor dentro del grupo de investigación Derecho Médico, Derechos Humanos y Bioética de la Universidad del Cauca, en el marco del proyecto de investigación "El secreto profesional. Análisis desde el derecho procesal y las garantías constitucionales".

** Estudiante de décimo semestre, en Derecho, Universidad del Cauca. Estudiante extranjero, en grado de Derecho, Universidad Carlos III de Madrid. Miembro del grupo de investigación Derecho Médico, Derechos Humanos y Bioética, Universidad del Cauca. Popayán. Colombia. Sus líneas de trabajo son Derechos fundamentales, Bioderecho y Filosofía del Derecho. Correo electrónico: sebasspor@unicauca.edu.co. ORCID: https://orcid.org/0000-0003-4865-3898. 
señalando las bases para su vigencia, sin intervención ni conocimiento externo, impidiendo el menoscabo del fuero interno por revelaciones unilaterales o intervenciones arbitrarias de terceros, que podrían vulnerar derechos fundamentales del paciente.

Palabras clave: derecho-deber, derechos fundamentales, personas con discapacidad, plena capacidad jurídica, secreto profesional médico.

\section{ABSTRACT}

Professional medical confidentiality is a constitutional guarantee of strict observance for the proper development of health sciences and the prevalence of some fundamental rights inherent to everyone, which represents a duty clinicians (understood as all health personnel) must perform invariably, avoiding the disclosure of the information he knows by reason of his profession to third parties, except legal exceptions. However, its exercise in Colombia is obscure regarding disabled people because despite their full legal aptitude the implementation of it is minimal. The figure of the tutor or third party with the capacity to make decisions in his/her name recurring in the sanitary relation, disagreeing with the personal character of that figure, which allows the required doctor-patient confidential relationship has precarious doctrine and legislation. It has intended to iterate its validity and safeguard persons with disabilities, allowing a bilateral relationship with the clinician, outlining its validity bases without intervention or external knowledge, preventing the undermining of its internal jurisdiction by unilateral revelations or arbitrary interventions by third parties, which could violate fundamental rights.

Keywords: Full legal capacity, fundamental rights, medical professional secrecy, people with disabilities, right-duty.

\section{RESUMO}

O segredo profissional médico constitui garantia constitucional de imperioso cumprimento para o idóneo desenvolvimento das ciências da saúde e prevalência de determinados direitos fundamentais, inerentes a todas as pessoas. Representa um dever que o galeno (quer dizer, todo pessoal sanitário) deve cumprir invariavelmente, evitando que a informação que conhecesse em razão de sua profissão seja divulgada a terceiros, salvo exceções legais. No entanto, seu exercício na Colômbia é escura respeito às pessoas com deficiência, pois, apesar de sua plena capacidade jurídica, pela exígua implementação do modelo social, é recorrente a figura do tutor ou terceiro habilitado para tomar decisões a seu nome, discrepando com o carácter personalíssimo de aquela figura que permite a relação de confidencialidade inescolhível entre galeno-paciente, em suma, possui doutrina e legislação precária. Se pretende reafirmar sua vigência e salvaguarda em pessoas com deficiência, permitindo uma relação bilateral com o galeno, assinalando as bases para sua vigência; sem intervenção nem conhecimento externo, impedindo o menoscabo do foro interno por revelações unilaterais ou intervenções arbitrárias de terceiros, que poderiam vulnerar direitos fundamentais do paciente.

Palavras-chave: direito-dever, direitos fundamentais, pessoas com deficiência, plena capacidade jurídica, segredo profissional médico. 


\section{Introducción}

El secreto profesional médico (secreto médico, de ahora en adelante) remonta su nacimiento a Hipócrates, quien lo consagró como garantía a la intimidad del paciente y derecho en cabeza del galeno, hasta el siglo XIX, cuando pasó a ser derecho del paciente (Barbero Gutiérrez, Sánchez Caballero, \& Martín Cortecero, 2013), inherente a todo ser humano, relativo a que el galeno no puede comunicar información que llegase a conocer del paciente a terceros, ni siquiera a las autoridades, por respeto a derechos del confidente y el interés público en el correcto ejercicio de la profesión (Fernández Carlier, 2015).

El secreto médico aboga por salvaguardar el fuero interno del paciente y adecuado devenir de la relación sanitaria (Barbero Gutiérrez, Sánchez Caballero, \& Martín Cortecero, 2013), íntimamente ligado con derechos fundamentales como la dignidad humana, la intimidad, la autonomía, la honra y la confidencialidad, e integrando el mecanismo de mayor importancia para la protección del "yo individual" del paciente, por lo que no es dable dudar sobre la prevalencia de su salvaguarda, salvo excepciones legales previas.

A pesar de ello, posee un estudio y desarrollo exiguo a nivel doctrinal y legislativo (Fajardo Sandoval, 2013), pues su regulación más amplia es la Ley 23 de 1981, que exclusivamente le dedica dos artículos relativos a su definición y excepciones, exhortando a que sean nuestras altas cortes las encargadas de regular su aplicación, ejerciendo función esencial la Corte Constitucional para decantar su preeminencia como garantía fundamental del paciente en la relación sanitaria.

Esta situación se agudiza en el caso de toda persona con alguna discapacidad, recalcando que la discapacidad se configura como un término genérico que engloba deficiencias, limitaciones de actividad y restricciones para la participación (Organización Mundial de la Salud [OMS] \& Organización Panamericana de la Salud [OPS], 2001 ); a pesar del desarrollo y avances realizados en la protección de una amplia gama de sus derechos, no se ha realizado avance alguno en este campo, y se encuentran en el olvido de todos los estamentos sociales, sin jurisprudencia, legislación o movimientos que pregonen un avance en la salvaguarda de su derecho al secreto médico. 
Contrario sensu, a nivel internacional se adoptó el modelo social mediante la Convención para los Derechos de las Personas con Discapacidad (CDPD, de ahora en adelante) que en su artículo 12 reconoce plena capacidad jurídica a toda persona con discapacidad, y pregona que su negación vulneraría el derecho a la privacidad (OHCHR, 2014); de esta manera, exhorta a los Estados a que dispongan de un sistema de ayudas potestativo conforme a las necesidades específicas de cada persona, ${ }^{1}$ que permita el ejercicio idóneo de sus derechos conforme a convicciones propias, empero, su asignación y características no puede depender de la evaluación de la capacidad mental, en razón a la diferencia entre esta y la capacidad jurídica, por lo que ello redundaría discriminatorio frente la persona con discapacidad (Comité de Naciones Unidas sobre las Personas con Discapacidad, 2014).

Ello, de ser encauzado en nuestro ordenamiento jurídico, erradicaría la imposición autoritaria de figuras como el curador o representante total, que actualmente se presenta como condición sine qua non en determinados casos, cuando desde la CDPD se ha pregonado que, independientemente del tipo de discapacidad, la persona tiene derecho al goce pleno de su capacidad jurídica, como al acceso a un sistema de ayudas accesible a sus necesidades (Benavides López, 2015).

Por otra parte, el modelo social de discapacidad la concibe como factor de diversidad en nuestra sociedad, resaltando que las únicas barreras que le sobrevienen son las implantadas por esta última (Quinn \& Degener, 2002), dejando atrás la concepción de impedimentos naturales o inherentes a la persona por su condición, conforme al reconocimiento de su plena capacidad jurídica, que permite el ejercicio autónomo de sus derechos, ergo, las barreras emanan de la errónea y falsa concepción social sobre la discapacidad, no de la naturaleza de la misma.

A pesar de esto, en nuestro ordenamiento jurídico y doctrina nacional, la literatura sobre la aplicación del sigilo médico en este grupo poblacional es nimia se extraña información sobre la aplicación del sigilo

\footnotetext{
Sobre ello, cito la catedra de clínica jurídica del Instituto de Derechos Humanos Bartolomé de las Casas, de la Universidad Carlos III de Madrid; "Todos necesitamos ayudas, tú necesitas gafas, asiento y demás, la única diferencia es que las ayudas de las personas con discapacidad son concretas, pero en sí todos necesitamos ayudas, y eso no te quita derecho al goce de tu plena capacidad jurídica".
} 
médico en este grupo poblacional, como también un reconocimiento inequívoco de su plena capacidad jurídica, debido a que este tema ha sido marginado a la dubitación, y se ha permitido que surjan ambigüedades e interpretaciones extensivas ${ }^{2}$ de legislación previa, basada en retazos del modelo rehabilitador que persisten en la sociedad colombiana, lo que perjudica aquel ejercicio autónomo y digno de derechos precitados; así pues, el presente texto se traza como objetivo esclarecer el tema de manera sistémica, con el objetivo de brindar luces sobre el quehacer en materia legislativa y social.

\section{Problema de investigación}

Corresponde a la situación de validez que posee, y debiere poseer, el secreto médico en las personas con discapacidad dentro de nuestro ordenamiento jurídico, teniendo en cuenta el Derecho Internacional, entendiendo que constituye una garantía constitucional concurrente a una amplia gama de derechos fundamentales, entonces, es necesario preguntarse ¿cuál es la validez y situación actual del secreto profesional médico en el caso de las personas con discapacidad, a la luz de su plena capacidad jurídica?

\section{Metodología}

El presente trabajo corresponde a una investigación científica con enfoque metodológico cualitativo, enfatizando en la descripción, análisis y propuesta respecto al problema de investigación. Se ha tomado como base la revisión de literatura cualitativa, como jurisprudencia, legislación y doctrina relevante, para delimitar el estado del arte y realizar un abordaje integral, que permita construir un aporte critico desde la académica conforme a las necesidades actuales.

2 Que suelen limitar la gama de derechos que poseen y se aparta de una interpretación sistemática. 


\section{El secreto profesional médico}

El presente acápite abordará un recorrido legal y jurisprudencial sobre la figura del secreto médico, develando inconsistencias y omisiones en su regulación desde la óptica de una crítica constructiva, con miras a exponer su estado del arte en nuestro ordenamiento jurídico.

Como se mencionó, el secreto médico inició su desarrollo cuando Hipócrates incoó en el juramento hipocrático: "Guardaré silencio sobre todo aquello que, en mi profesión, o fuera de ella, oiga o vea en la vida de los hombres que no deban ser públicos, manteniendo estas cosas de manera que no se pueda hablar de ellas" (Córdoba Palacio, 1990).

Desde entonces, dicho juramento ha sufrido cambios; de antaño se entendía como un derecho en cabeza del galeno, y actualmente le representa un derecho-deber como derecho del paciente, el cual se encuentra salvaguardado en el artículo 74 de la Constitución de Colombia, por su estrecha relación con derechos/principios constitucionales como la dignidad humana, la intimidad, la autonomía, la honra y el buen nombre, entre otros, siendo definido en el artículo 37 de la Ley 23 de 1981, como:

Aquello que no es ético o lícito revelar sin justa causa. El médico está obligado a guardar el secreto profesional en todo aquello que por razón del ejercicio de su profesión haya visto, oído o comprendido, salvo en los casos contemplados por disposiciones legales.

Sin embargo, la anterior definición otorga una remisión ética y legal en blanco. Esta última, en razón a su exiguo desarrollo legislativo, pues aunque se consagró en los códigos deontológicos de las profesiones en ciencias de la salud, ${ }^{3}$ nuestro ordenamiento jurídico ha sido incapaz de solventar las controversias que se suscitan en la actividad diaria del galeno, negándole una salvaguarda efectiva, y si bien, el respeto y protección al sigilo médico no depende exclusivamente de una regulación positiva, constituiría un 
avance representativo para su desarrollo y prevalencia efectiva. Referente a la primera, se debe al carácter exánime de la ética en este campo, por las subjetividades y pluralismo que le inhiben de la certeza necesaria para generar seguridad jurídica y redunda en una definición vacua.

Vemos que, además del exiguo desarrollo legal que se ha emprendido, la nimia actividad de nuestro legislador deviene en incorrecta, y desampara la prevalencia del sigilo en las personas con discapacidad, inhibiéndole de aspectos básicos, como una definición satisfactoria, por lo que, se propone entender el sigilo médico como el derecho fundamental, por conexidad, que obliga al profesional de la salud a salvaguardar del conocimiento de terceros toda información del paciente, o relacionada, que llegase a adquirir en razón a su profesión, independientemente de la fuente que haya emanado, obligándose hasta después de la muerte del paciente, o finalización de la relación sanitaria, como señala el juramento hipocrático.

Categoría de fundamental otorgada por la preminencia conferida en nuestra carta política y su correspondiente jurisprudencia constitucional, pues, aunque no se estipula literalmente, con su afección se transgreden de manera simultánea derechos fundamentales como la intimidad, la autonomía, la confidencialidad, el buen nombre y la honra del sujeto pasivo, por ende, puede considerársele como fundamental por conexidad.

En suma, su protección encuentra asidero en su carácter iusfundamental (particular) y la confianza inescindible que debe nacer del paciente hacía el galeno (general), resguardada por el sigilo, ya que toda persona ve en su esfera íntima uno de los aspectos de mayor relevancia en su vida, representando la parte más íntima de su individualidad que se oculta del escrutinio público en una sociedad abrumadora, pluricultural e intolerante como la actual. Por tanto, si esa confianza se descompone, la relación sanitaria y su efectividad tendrían el mismo devenir por la falta de información y confianza que impediría el desarrollo idóneo de la actividad médica.

En contra de la importancia reseñada, y las amplias características esenciales dentro de una sociedad que le conminan al secreto médico, su legislación y doctrina es nimia, prácticamente inexistente, exhortando a que las altas cortes procedan a suplir el yerro legislativo respecto a las características, implicaciones y requisitos de esta figura; a pesar de ello, 
observamos que en los casos relacionados con minorías, como las personas con discapacidad, los avances realizados son prácticamente inexistentes.

Frente a citados yerros, se requiere acentuar su prevalencia y efectiva aplicación en las relaciones sanitarias frente a todo tipo de pacientes y contextos, pues, como derecho fundamental, debe ser respetado por parte del galeno a toda persona, conforme a sus necesidades específicas y a excepciones legales previamente consagradas, bajo el entendido de las consecuencias directas que acarrearía su desconocimiento en el ámbito social y personal del perjudicado, por lo que se hace necesario una regulación específica que garantice la efectividad clara e idónea de esta figura frente a los retos que suscita el ejercicio diario de la medicina, pues no es dable avocar un desarrollo jurisprudencial que aborde integralmente los casos específicos y las controversias que se suscitan en esta figura.

Habiendo visibilizado la importancia constitucional del secreto médico, resulta menester aclarar que la obligación de su salvaguarda no corresponde exclusivamente a mandatos nacionales; la Corte Interamericana de Derechos Humanos, en la sentencia de Fondo, Reparaciones y Costas del caso De la Cruz Florez vs. Perú, señaló que:

La información obtenida por el médico en el ejercicio de su profesión se encuentra privilegiada por el secreto profesional, en virtud de su derecho-deber de guardar confidencialidad sobre la información a la que tenga acceso en su condición de galeno, por ende, no puede ser molestado ni sancionado por guardar el secreto médico, todo lo contrario, solo podría ser amonestado en caso de su revelación. (Corte Interamericana de Derechos Humanos, 2004)

A nivel supranacional, el Comité de Derechos Humanos ha recomendado a todos los Estados miembro introducir modificaciones en su legislación interna para garantizar la confidencialidad de la información médica (UN Human Rights Comittee, 1999), en aras de la custodia que se le debe brindar a la intimidad y confidencialidad del paciente en la relación sanitaria, aspecto que, si bien ha sabido suplir la jurisprudencia constitucional, remarca la necesidad apremiante de una regulación específica con la capacidad de atender casos complejos y situaciones específicas, con claridad para la comunidad sanitaria y población en general, que en muchas ocasiones se ve obligada a presenciar el pérfido incumplimiento y transgresión de este derecho. 
En muchas ocasiones se pierde la conciencia respecto a lo que representa vulnerar el secreto médico (Romeo Casabona, 2011) para ambas partes en la relación galeno-paciente, negándole la importancia que merece, lo cual puede enmarcarse como una de las principales causas en la decadencia actual de los servicios de salud en nuestro país, y el gran número de acciones judiciales y administrativas incoadas contra el mismo, razones que exhortan a consagrar la salvaguarda y efectividad de este derecho como una de las obligaciones de mayor urgencia en la práctica sanitaria.

\section{Derechos vinculados al secreto médico}

Como se ha visto, corresponden a una amplia lista de derechos, que inclusive responden a la categoría de fundamentales; sin embargo, atendiendo a la extensión del escrito, no es posible abordarlos en su integridad, por lo que se analizarán los Principios/Derechos a la intimidad, la confidencialidad y la autonomía, en virtud a su interdependencia con el secreto médico y la posibilidad de estudiar desde su luz derechos fundamentales como la honra, el buen nombre, la libertad y la dignidad humana.

\section{Intimidad}

La supremacía del principio/derecho a la intimidad ha sido ampliamente decantada en la comunidad nacional e internacional ${ }^{4}$ debido al dinamismo del contexto actual, que exhorta al fortalecimiento exponencial de la naturaleza social del ser humano, generando que el fuero interno de cada persona constituya uno de los bienes jurídicos protegidos con mayor esmero y recelo por cada individuo.

La Corte Constitucional,, en sentencia T-708 de 2008, manifestó que aquel permite y garantiza una esfera de vida privada no susceptible de la interferencia arbitraria de terceras personas que, considerado un elemento

4 Véase el artículo 12 de la Declaración Universal de Derechos Humanos; el artículo 17.1 del Pacto Internacional de Derechos Civiles y Políticos; el artículo 8.1 del Convenio para la protección de los Derechos Humanos y las Libertades Fundamentales y el artículo 11.2 de la Convención Americana sobre Derechos Humanos, entre otros. 
esencial del ser, se concreta en el derecho a poder actuar libremente al interior de mencionada esfera o núcleo, en ejercicio de la libertad personal y familiar, sin más limitaciones que los derechos de terceros y el ordenamiento jurídico (Vargas Hernández, 2008), configurando un ámbito inescindible en la existencia de todo ser humano, que no es permitido vulnerar, salvo excepciones legales.

Este derecho, materializado como la intimidad metafísica fundamental en la existencia centrípeta del yo individual de cada persona, representa una característica sustancial de la dignidad humana, que permitió su consagración como derecho fundamental en nuestra carta magna, e igualmente una amplia gama de derechos fundamentales que dependen de su salvaguarda, entendiendo que su respeto le es intrínseco a todo ser humano por el valor que posee cada persona en su individualidad, lo cual podría verse constreñido al invadir arbitrariamente señalada esfera privada.

En el marco de la relación galeno-paciente, todo lo anterior queda supeditado al idóneo proceder de aquel, pues este último, como lo señaló la Corte Constitucional en sentencia C-264 de 1996, permite la entrada y conocimiento de su fuero interno al galeno, al sector más centrípeto de su "yo individual", a pesar de que dicho ingreso representa una limitación a la libertad casi absoluta que gozaba en su intimidad, pues el profesional supera la barrera protectora de la vida privada del paciente (Cifuentes Muñoz, 1996) como resultado de la confianza que el paciente otorga al galeno en cumplimiento de su deber profesional.

Ahora, ¿qué pasaría si dicha discrecionalidad desapareciera? iEl galeno flagela el secreto! No sería necesaria una divulgación masiva, pues con la simple comunicación a un tercero, la intimidad del paciente se reduce a la mínima impresión, su autonomía se ve afectada por la exteriorización arbitraria de su información por un tercero, quebrantando la posibilidad de que galeno-paciente se comuniquen satisfactoriamente e impidiendo así una relación sanitaria satisfactoria.

Como consecuencia, el respeto a la intimidad y el sigilo médico representa una obligación que supera preceptos legales, teniendo en cuenta el pacto implícito de confianza que nace al establecerse la relación sanitaria, referente al deber ético de todo galeno, ${ }^{5}$ que propicia la confianza que

5 Entendiendo que no se puede configurar como un deber moral, en razón a la complejidad 
en él se instaura (Ablanedo Suárez, 2015) y permitiéndole al paciente abrir las puertas de su fuero interno, en miras al idóneo desarrollo de la labor médica, quien confía en que su información será resguardada con el mayor profesionalismo y cuidado posible.

Cabe también preguntarse qué pasa en la relación galeno-paciente con discapacidad, y la figura del curador. Si se revela información privada al curador, se vulneraría todo lo antedicho, pues las personas con discapacidad poseen plena capacidad jurídica, que les permite ejercer la integralidad de sus derechos en igualdad de condiciones a cualquier otro ciudadano de manera plena y autónoma, sin que la CDPD hubiere establecido ningún tipo de distinción entre capacidad de hecho y de derecho para el caso específico, ni tampoco entre los diferentes tipos de discapacidad, por lo que, sin autorización previa, el tutor, representante o similar pueden tener acceso a información privada del paciente en el ámbito sanitario como la historia clínica, tratamiento o demás.

\section{Confidencialidad y autonomía}

En el ámbito de la salud, la confidencialidad se ha definido como la obligación del personal sanitario de proteger la información del paciente y no divulgarla sin autorización (Organización Mundial de la Salud [OMS], 2003) para preservar su mundo interior incólume frente a la sociedad. A lo largo de la historia, ha sido abordado desde diferentes perspectivas, sobresaliendo las teorías consecuencialistas y deontológicas que califican negativamente la afectación a la intimidad del paciente.

Desde una visión consecuencialista, cuando un médico viola la confidencialidad produce un daño individual y social, ya que los pacientes perderían confianza en los profesionales de la salud (Iglesias Díez, 2017), afectando de manera significativa y trascendental la efectividad, adherencia y confidencialidad en la relación sanitaria, lo que provocaría la pérdida de confianza hacia el galeno (Barbero Gutiérrez, Sánchez Caballero, E Martín Cortecero, 2013).

Desde la óptica deontológica, se menciona que la confidencialidad puede ser considerada una regla moral derivada del principio de autonomía

de su aplicación en el mundo diverso y pluricultural actual. 
(Beauchamp \& Childress, 1999) que recae en todo ser humano, y el galeno en el ejercicio de su profesión debe corresponder a esta regla moral ${ }^{6}$ prestablecida. Según el principio de autonomía, toda persona humana es libre y tiene derecho a tomar decisiones sobre su vida, constituyéndose en único responsable de las mismas, siendo la confidencialidad un valor instrumental a este principio, ya que se erige como garantía frente a la intromisión de terceros en la esfera íntima (Iglesias Díez, 2017).

La autonomía, entonces, representa un derecho intrínseco a cada ser humano, ya que no de nuestro mérito, condición social o poder adquisitivo (Valdés, 2011), sino que es una condición que poseemos por la simple condición de ser personas. En adición, se encuentra íntimamente ligada con el ejercicio efectivo de la intimidad, la privacidad e, inclusive, la dignidad humana (Rendtorff, 2002), debido a lo cual constituye condición sine qua non para el goce pleno de los derechos fundamentales, que podría verse afectada por la decisión unilateral del galeno de hacer pública la información exclusivamente a él confiada (Antomás Osés E Huarte del Barrio, 2011).

Así las cosas, a partir de la teoría deontológica, el principio de confidencialidad per se no posee rol principal en la gama de derechos/obligaciones endógenos al ser humano; sin embargo, cumple una función preponderante para la consecución del principio de autonomía, por tanto debe ser respetado independientemente de características exógenas, pues su desconocimiento conllevaría el irrespeto de sus derechos fundamentales que no pueden desatenderse bajo ningún contexto; por ende, la importancia y prevalencia de la confidencialidad es un aspecto insoslayable, exhortando a que su respeto constituya regla general.

De este modo, es dable argüir que la confidencialidad y autonomía son principios básicos de la relación asistencial, promovidos moralmente y protegidos legalmente en beneficio de todo ser humano, una vez que la integridad de la población posee un fuero interno que debe ser salvaguardado de intromisiones arbitrarias de terceros, debido a que constituyen parte esencial al ser individual de toda persona, propio y exclusivo de esta, que debe ser respetado por el galeno mediante el secreto médico,

6 En relación, se reitera la complejidad de la aplicación actual de reglas u obligaciones morales, por lo que, se recomienda interpretarlas a la luz de obligaciones éticas y deontológicas. 
permitiendo un adecuado ejercicio de la medicina, pues, como afirman Ramos, Montes y Gabaldón Fraile (2012) “No hay medicina sin confianza, ni confianza sin confidencia, ni confidencia sin secreto".

\section{Plena capacidad jurídica de las personas con discapacidad y sus consecuencias}

La plena capacidad jurídica está compuesta por dos dimensiones; una estática (de goce o de derecho), representada por la titularidad de derechos y obligaciones, y otra dinámica (de ejercicio o de hecho), que constituye el ejercicio de los mismos (Bariffi, 2009); en esta última convergen las más amplias modificaciones impulsadas por la CDPD (De Asís, 2009) que engloban ambas dimensiones y reconocen la plena capacidad jurídica de hecho y de derecho a toda persona con discapacidad sin distinción de cuál sea esta (Comité de Naciones Unidas sobre las Personas con Discapacidad, 2014), permitiendo su ejercicio autónomo, con el respeto de un sistema de ayudas o apoyos potestativo conforme a sus características específicas (Benavides López, 2015), reseñando que "La plena capacidad jurídica es la puerta de acceso al ejercicio de todos los derechos" (Bariffi, 2009, p. 359).

Entonces, se presenta como condición sine qua non para ejercer de manera idónea los derechos propios de cada individuo, y, por ende, poseer un rol participativo dentro de la sociedad, pues carecer de ella implica que otra persona se vea compelida para decidir por quien no la posee, invadiendo su esfera íntima, individual y privada en todos los ámbitos e impidiendo que participe individualmente en la sociedad; lo anterior, como ha señalado la Corte Constitucional, constituye uno de los mayores fundamentos para que la CDPD imponga a los Estados (Ortiz Delgado, Gloria, 2016);

De una parte, la obligación de abstenerse de cualquier medida que prive a las personas con discapacidad del reconocimiento de su capacidad jurídica, y, de otra parte, el deber de garantizar que los particulares no interfieran con el ejercicio de la capacidad jurídica de estos sujetos. En consecuencia, los Estados tienen un mandato para reemplazar los 
regímenes basados en la adopción de decisiones sustitutivas por sistemas de apoyo a la adopción de decisiones. Estos últimos se caracterizan por la primacía de la voluntad de la persona con discapacidad, su autonomía y preferencias. De este modo, los Estados partes no deben negar a las personas con discapacidad su capacidad jurídica, sino que deben proporcionarles acceso al apoyo que necesiten para tomar decisiones que tengan efectos jurídicos. (p. 34)

Lo anterior, ha sido cuestionado a nivel internacional, al señalar que debe diferenciarse entre la discapacidad cognitiva y física por las consecuencias directas que cada una acarrea, pues interpretar que se reconoce capacidad de hecho y derecho en todos los tipos de discapacidad perjudica de manera directa la prevalencia y efectividad de los regímenes de tutela y condiciones dignas de existencia, especialmente en el caso de la discapacidad cognitiva (Solé, 1016), entonces, debería adoptarse un tratamiento especial en el acceso al sistema de ayudas y tutores, mediante una presunción iuris tantum de su capacidad de ejercicio.

Sin embargo, seguir lo antedicho contrariaría el modelo social, según el cual las causas de la discapacidad se encuentran en la propia sociedad que minusvalora y discrimina a este grupo que es tan digno, autónomo, igual y libre como el resto (Quinn \& Degener, 2002), y le imprime un valor positivo a la discapacidad, eliminándole el rótulo de mal o enfermedad, enfatizando la idea de la persona con discapacidad como ser digno e igual (Fernández, 2010), respetando la posición personal, autónoma e intangible que le corresponde a cada individuo, pues independiente de la discapacidad cognitiva o física, la persona tiene derecho al reconocimiento de su capacidad jurídica en igualdad de condiciones (UN, 2006), teniendo el Estado la obligación, en todos los casos, de otorgar un sistema de ayudas conforme a las características de cada individuo, que permita el ejercicio pleno de todos los derechos de este grupo poblacional, en desarrollo de los derechos fundamentales de igualdad y dignidad humana, por lo que el presente escrito aborda la discapacidad desde todas sus modalidades sin ningún tipo de discriminación entre la cognitiva y física.

La plena capacidad jurídica se encuentra reconocida a las personas con discapacidad, y, si bien nuestro ordenamiento jurídico ha realizado avances al respecto, a nivel material es necesario plantear un desarrollo 
conciso encaminado a modificar nuestra legislación civil, que permita el goce efectivo de sus derechos sin desatender el sistema de ayudas conforme a las características específicas, buscando superar la barreras sociales que injustamente se erigen en su contra, pues, como señaló la Corte Constitucional en la sentencia C-182 de 2016, la discapacidad per se, no da lugar a la negación de ningún derecho, mucho menos, uno contenido en la CDPD (Ortiz Delgado, 2016).

En este sentido, se debe aclarar que el sistema de ayudas, modelo social y el reconocimiento de su plena capacidad jurídica corresponden a un amplio recorrido y esfuerzo histórico en pugna de sus derechos, pues se han sobrepasado modelos que les consideraban de menor valor que otra persona (modelo de prescindencia) o como una tara médica (modelo médico), ${ }^{7}$ que deben ser exiliados con el objeto de no iterar en flagelos cometidos antiguamente, como acaecía en la relación médica, pues poseen la misma gama de derechos que cualquier persona, aunque en el ámbito sanitario continua existiendo una visión paternalista que no les reconoce el ejercicio autónomo de sus derechos.

Las personas con discapacidad tienen derecho a acceder a los servicios sanitarios en igualdad de condiciones a cualquier ciudadano, incoar al Estado en la adopción idónea y eficaz del sistema de ayudas conforme a sus necesidades concretas, evitando todo tipo de discriminación o trato perjudicial, pues su plena capacidad jurídica permite que sea la única persona con potestad de tener información relativa a su tratamiento, y brindar consentimiento informado y demás, que solo podría acceder un tercero en caso de autorización previa, inclusive si versara sobre discapacidad cognitiva.

Así las cosas, en la relación sanitaria, la plena capacidad jurídica implica el reconocimiento del paciente como "persona" en sentido pleno y dotado, mientras no se pruebe lo contrario, de la capacidad para ejercer y disponer de los derechos que le pertenecen, no ser cosificado o menospreciado por el personal sanitario, que tiene la obligación de guiar su actuar conforme a los principios bioéticos de autonomía, no maleficencia,

7 Para profundizar en este aspecto, se puede consultar Portilla Parra, S. (2019). Implicaciones Jurídicas del Método de Edición Genética CRISPR-Cas9, y su aplicación en personas con discapacidad. Papeles el Tiempo de los Derechos. No 9. 
beneficencia y justicia, todos los cuales, en especial los dos primeros, se encuentran íntimamente ligados con la prevalencia del secreto médico, el consentimiento informado y todas las garantías sanitarias (entiéndase secreto profesional, consentimiento informado y demás) existentes en la relación galeno-paciente, que se vulnerarían en caso de permitir la interfería arbitraria o unilateral de un tercero, desconociendo la autonomía y opinión propia de la persona con discapacidad.

De esta forma, también se obliga a superar el paternalismo médico que permitía al galeno decidir en forma unilateral el tratamiento a seguir, lo que trasladaría al paciente la potestad de decidir el curso del actuar médico, que solo podría ser coartado en caso de que el paciente así lo decida de forma clara, expresa y previamente.

Esto hace parte de los avances logrados con la CDPD, que se encaminan a la progresión de sus derechos, y deben verse a la luz del principio pro homine y el valor inherente que posee todo individuo, conforme a los derechos que le son propios y el DIDH, para superar los pérfidos flagelos y transgresiones inhumanas que han sufrido a través del tiempo, imponiendo un deber mayor al Estado para el respeto y salvaguarda efectiva de los mismos, evitando yerros pasados.

Por otro lado, conforme a una lectura sistémica de la CDPD, todo Estado debe poner a disposición de la comunidad con discapacidad un sistema de ayudas que permita superar las barreras y obstáculos sociales impuestos, sin embargo, ello no representa desconocer la idoneidad y veracidad del modelo social, todo lo contrario, reconoce las barreras sociales que enfrentan, las cuales, dependiendo de factores exógenos y endógenos, requieren mayor atención y colaboración externa para ser superadas.

Entonces, para el pleno desarrollo e implementación del modelo social, se hace necesaria la adopción integral de un sistema de ayudas que satisfaga los ámbitos apremiantes de este colectivo. Aspecto en el cual se extraña mayor laboriosidad estatal, pues el Estado colombiano ha desplegado un actuar omisivo y sin mayor profundidad al desatender los avances internacionales en este tema, sin regular ni implementar de manera satisfactoria la plena capacidad jurídica bajo estudio, requiriéndose una transformación vertical tocante a todas las instituciones y estamentos sociales, publicitando y respondiendo ante las obligaciones que impone 
la comunidad internacional en este ámbito, como bien lo han realizado Estados como el peruano o el español.

Respecto a la plena capacidad jurídica, si bien no se menciona el caso del sigilo médico, en el derecho comparado constituye una valiosa guía el Decreto Legislativo 1384 de 2018 del Perú, que reconoce y regula la capacidad jurídica de las personas con discapacidad en igualdad de condiciones, elimina la figura de la interdicción, entre otras disposiciones civiles y procesales, que permiten el ejercicio autónomo de derechos para este grupo, junto a su plena capacidad jurídica y la potestad de acudir a un sistema de ayudas capaz de satisfacer las necesidades específicas de cada sujeto. Una regulación semejante, como se ha mencionado, sería necesaria en nuestro marco jurídico nacional y es de imperiosa realización, claro está, con ciertas observaciones preliminares que persigan el respeto y salvaguarda eficaz de los derechos en cabeza de personas con discapacidad a través de los medios idóneos para su eficaz goce y disposición.

Por su parte, la Corte Interamericana de Derechos Humanos, en la sentencia del Caso Ximenes Lopez vs. Brasil, manifestó que las personas con discapacidad como consecuencia de su estado de debilidad manifiesta, y al ser objeto de discriminación a raíz de su condición, deben ser beneficiarias de medidas de carácter legislativo, social, educativo, laboral o de cualquier otra índole, necesarias para que toda discriminación o irrespeto al derecho a la igualdad sea eliminado de manera mancomunada al sistema de ayudas pregonado por la CDPD (Ximenes Lopez vs Brasil, 2006).

Esta línea es respaldada por nuestra Carta Magna, que desde el preámbulo consagra los derechos de las personas con discapacidad y garantiza su protección especial en el artículo 13; sin embargo, en la realidad no se refleja este avance, pues continúan existiendo contextos de discriminación o minimización, denominaciones peyorativas, las cuales son retazos del modelo de rehabilitación (Portilla Parra, 2019) viendo a estas personas como seres vacuos y sin valor, tolerando figuras como la del tutor; ejemplo de lo anterior es que nuestro ordenamiento declara incapaz a todo "sordomudo" que no pueda darse a entender, ${ }^{8}$ contrario al mandato constitucional y el desarrollo internacional.

8 Véase el artículo 1504 del Código Civil de Colombia. 
A manera de conclusión, se debe establecer la necesidad de regular la plena capacidad jurídica de las personas con discapacidad, el sistema de ayudas y su aplicación, así como el acceso al sigilo médico y demás garantías en el ámbito sanitario (y todo contexto posible), dado que, concomitantemente al bloque de constitucionalidad en sentido lato, actualmente son figuras que reposan en cabeza de toda persona con discapacidad a la luz del ordenamiento jurídico internacional, que se introduce a nivel interno, aunque encuentra diferentes restricciones para su aplicación en el contexto social y normativo vigente de nuestro país, aspecto que debe delimitarse mediante la adopción de un marco legal especifico y claro para su prevalencia y salvaguarda, que afecta directamente la vigencia de un amplio número de derechos fundamentales señalados previamente.

\section{Secreto médico y personas con discapacidad}

En el presente acápite se concatenarán ambos tópicos tratados en precedencia, incursionando dentro de un tema que ha sido invisibilizado desde todas las ópticas posibles, pues los estudios específicos al respecto han sido nimios, respondiendo también a una normalización del modelo rehabilitador, que permite la vulneración de este derecho en cabeza de la persona con discapacidad y, contrario al deber ser, es consuetudinario en nuestra sociedad, olvidando las consecuencias insoslayables que acarrea su irrespeto.

El secreto médico ha sido una figura de amplísimo desarrollo en la comunidad internacional, que, junto a las providencias de Corte Constitucional, han reseñado como su fundamento último la protección de derechos iusfundamentales representados en la intimidad, autonomía, confidencialidad, dignidad humana, entre otros, inherentes a todo individuo por su condición de ser humano.

Empero, el desarrollo y suficiencia al interior de nuestro ordenamiento jurídico ha sido exiguo, y en casos específicos, como el de las personas con discapacidad, ha sido ínfimo y fútil a causa de la limitada implementación del modelo social y desarrollo legislativo, inclusive, es dable manifestar que esta última omisión menoscaba la prevalencia y aplicación efectiva de aquella garantía, y puede conllevar la afamada 
responsabilidad del Estado por omisión legislativa, porque los derechos y garantías constitucionales que se ven perjudicados por esta omisión responden a una amplia lista.

Esta preocupación no solo debería atender a miramientos desde la academia o sectores minoritarios, pues Naciones Unidas ha enfatizado en la potestad que tienen las personas con discapacidad para decidir sobre su salud en igualdad de condiciones a cualquier individuo, exhortando a todo Estado a respetar y garantizar su efectivo cumplimiento (Comité de Naciones Unidas sobre las Personas con Discapacidad, 2014), entendiendo que la omisión en la observancia efectiva del mentado precepto constituiría responsabilidad para el Estado, que no solo se configura por acción, sino también por su aquiescencia u omisión al regular y salvaguardar este derecho, ya que afecta la autonomía y dignidad de la persona.

Ahora, respecto a las garantías que merecen las personas con discapacidad dentro de la relación sanitaria, es errónea la tesis que se ha predicado por parte de la doctrina, relativa a que cuando el evaluado posee discapacidad cognitiva será el tutor quien dará su consentimiento informado en el tratamiento médico (Hernández, 2013) y conocerán la información relativa al tratamiento médico, lo cual, a la luz de la CDPD y manifestaciones de la comunidad internacional, va en perjuicio de su autonomía y dignidad, como se ha manifestado en precedencia.

Así, independientemente del tipo de discapacidad que posean (física, cognitiva, auditiva...), su plena capacidad y derechos deben ser respetados en el ámbito sanitario a cabalidad, incluyendo mantener incólume la historia clínica, secreto médico, consentimiento informado, decisión sobre su tratamiento y demás, que no puede ser encomendado a un tercero sin previa autorización del paciente, en donde pierde la autoridad que fácticamente ostenta en tutor o representante de la persona con discapacidad frente al galeno, pues toda persona con discapacidad consciente tiene derecho a que ello permanezca bajo su esfera íntima y personal, desmontando la tesis de taras o deficiencias naturales o necesidad de intervención por parte del tutor que se creían ciertas en el modelo de prescindencia.

En cualquier caso, aquella información solo podría ser develada a otra persona en contextos de urgencia o inconsciencia del paciente, en donde es una fuerza mayor la que impele a la citada revelación, pero en ningún caso este tipo de actuar podrá encontrar asidero en la capacidad mental. 
En caso contrario, podríamos evidenciar cómo la prestación del servicio sanitario y la relación galeno-paciente se menoscabada en las personas con discapacidad, conjuntamente a la intimidad y confidencialidad que en el caso específico de este grupo poblacional debería ser salvaguardada con mayor ahínco (Ramos Montes \& Gabaldón Fraile, 2012), pero se vulnera cuando el tutor (o similar) se presenta como figura menester e indispensable en la toma de sus decisiones, inhibiéndoles de una efectiva participación en nuestra sociedad junto al goce pleno de sus derechos y garantías constitucionales, como el secreto profesional, de forma libre y autónoma.

De acuerdo con la CDPD, toda persona con discapacidad, independiente del tipo o de sus características específicas, se encuentra en la capacidad de comprender conscientemente su condición, de este modo, el revelar su secreto médico constituiría una grave lesión a su autonomía (Ramírez Ortegón, 2009), dignidad humana y fuero interno; por tanto, no puede aducirse argumento que otorgue validez a aquella revelación, que no puede ser tolerada bajo ningún contexto, entendiendo que todo ser humano es un fin en sí mismo, y no es dable condescender a la vulneración de su dignidad (Kant, 1999), como, infortunadamente, de antaño se ha realizado en perjuicio de este grupo.

Lo precedente no puede interpretarse como una retórica estrafalaria limitada a la academia, todo lo contrario, se realiza con miras a visibilizar un actuar afable respecto a este grupo, su plena capacidad y derechos, con énfasis en el sigilo médico, entendiendo que este último constituye una garantía constitucional que ampara una diversidad de derechos fundamentales, y no podría ser aplicado adecuadamente si olvidamos el reconocimiento de su plena capacidad jurídica.

Como mencionó la Corte Constitucional en sentencia C-264 de1996, se requiere un actuar interdisciplinar y completo que efectúe una plena inserción legal y social del tópico bajo estudio y que logre su aplicación en la práctica médica, protegiendo derechos inalienables como la autonomía, la confidencialidad, la dignidad e intimidad, dado que: "el "yo de cada individuo" está protegido por la Constitución Política y su profanación o puesta en conocimiento público es una afrenta injustificada a este mundo interior e individual" (Cifuentes Muñoz, 2016, p. 15). 
También se debe emprender la salvaguardia integral del secreto médico por parte de todo profesional en las ciencias de la salud a favor de toda persona, salvo excepciones legales preexistentes, en razón a la importancia social e individual que el mismo posee y fortalecida en el caso de las personas con discapacidad como sujetos de especial protección constitucional que precisan, como todo ser humano, el goce de una relación íntima y de confianza con el galeno, que constituye condición inescindible para el buen devenir del ejercicio médico.

Ahora, no es erróneo afirmar que la comunidad de profesionales de la salud cumplen un papel trascendental en la vida de las personas con discapacidad, pues un considerable número de ellos debe asistir constantemente a sus servicios, llámese fisioterapeuta, psicólogo, optómetra, fonoaudiólogo..., despojándose de parte de su intimidad, en perjuicio de su fuero interno, con la expectativa de una prestación digna y profesional del servicio de salud, que respete y proteja la información adquirida, por ende, no puede admitirse, ni mucho menos legitimarse, que información perteneciente a su fuero interno sea develada a terceros, independiente del nombre que tome, ya que, en caso de defraudar citada expectativa, ¿cómo se podría pedir que el paciente nuevamente permita el ingreso a su fuero interno y brinde la información necesaria para el proceso médico, después de haber visto irrespetados sus derechos?

Se perdería totalmente la confianza y seguridad entre galeno y el paciente, afectando el desarrollo de la profesión médica, en perjuicio de los derechos enunciados a lo largo del texto, e indirectamente el derecho a la salud de la persona con discapacidad, pues perdería la confianza depositada en el galeno, que podría devenir en una desconfianza generalizada ante toda la comunidad sanitaria, impidiendo que brinde toda la información necesaria para el tratamiento y curación del mal que le aflije (dejando en claro que la obligación del médico es de medio, no resultado).

Por todo lo anterior, no es posible que el galeno se vea relegado de su derecho-deber respecto a la salvaguarda del sigilo medico en caso de las personas con discapacidad, todo lo contrario, en este tipo de ocasiones su prevalencia adquiere especial valor por todo lo reseñado; en suma, el secreto profesional se funda en la intimidad propia del paciente, su "yo individual", que le es intrínseco a toda persona, sin miramientos a factores exógenos, simplemente requiere que la persona sea capaz de 
representarse en su realidad, lo cual, al poseer plena capacidad jurídica, le es inherente a las personas con discapacidad, adquiriendo total derecho para su disfrute y la prevalencia de los derechos iusfundamentales que protege el secreto profesional, y no pueden obviarse por su rol de garantía constitucional.

\section{Resultados de investigación}

Después de revisado el estado del arte respecto a los tópicos que integran el problema de investigación, se observa, en el ámbito legislativo, el secreto médico en el ámbito posee un desarrollo anodino, y la doctrina no ha sido del todo ajena a esta omisión, permitiendo que su aplicación se relegue a un limbo jurídico que puede ser dirimido de forma discrecional por el galeno, lo cual podría perjudicar los derechos del paciente y objetivos del secreto, incoando a que la Corte Constitucional desarrolle un papel fundamental en su reglamentación, ofreciendo parámetros básicos respecto a su aplicación, desarrollo y límites, a sabiendas de que este no es el rol de un tribunal constitucional, y consecuentemente, ha resultado insuficiente.

Así las cosas, dentro del ordenamiento jurídico colombiano, el secreto médico representa una garantía constitucional en cabeza del paciente, amparado por el artículo 74 de la carta magna y el bloque de constitucionalidad en sentido lato, mediante una amplia gama de convenciones internacionales y jurisprudencia de la Corte Interamericana de Derechos Humanos, garantía que por regla general debe ser respetada, salvo excepciones consagradas en el artículo 38 de la Ley 23 de 1981, constituyendo un derecho-deber para el galeno, que se encuentra en la obligación de procurar la salvaguarda de toda información que llegase a conocer en razón de su profesión, pues en sus manos radica la base fundamental para el éxito de la ligación sanitaria, como lo es la confianza y privacidad existente entre el galeno y el paciente.

El sigilo médico, entonces, protege la parte intrínseca de todo individuo, representada en la intimidad, la dignidad humana, la autonomía y la confidencialidad, entre otros, que además de amparar el fuero interno e íntimo del paciente dentro de la relación sanitaria, vela por la efectividad 
de esta última, luego entonces, prima facie no habría lugar a dudas respecto su vigencia y aplicación.

Sin embargo, a nivel nacional, el caso de las personas con discapacidad no posee estudios o desarrollo suficiente, permitiendo que su aplicación se reduzca a un limbo jurídico mayor, que extraña una respuesta con vocación a certeza, y permite que la salvaguarda del sigilo sea invadida en amplia medida por la subjetividad del galeno, relegando a un segundo plano la prevalencia y derechos del paciente, debido a diversas razones, como la prexistencia de modelos antiguos de la discapacidad y la ausencia de atención social y estatal, entre otros.

Por ello, fue menester realizar un análisis extensivo de la situación en la comunidad internacional, que, con la CDPD como cúspide, goza de un entorno con mayores luces, adoptando el modelo social al reconocer la plena capacidad jurídica de esta población junto a un sistema de ayudas conforme a sus características específicas, que permitió arribar a la conclusión de garantía y salvaguarda prevalente que debe existir ante toda la gama de derechos pertenecientes a las personas con discapacidad de manera autónoma y digna, incluyendo, claramente, el secreto médico.

Resulta imperioso adoptar efectivamente en nuestro ordenamiento jurídico los buenos avances de la CDPD y la comunidad internacional, con el objetivo de garantizar de forma plena el secreto médico y su aplicación efectiva en el caso de las personas con discapacidad, conforme a la lista de derechos fundamentales que le sobrevienen y son salvaguardados por la misma, acentuando la obligación del galeno relativa a respetar la plena capacidad jurídica que aquel posee, junto a la capacidad para decidir y autodeterminarse en el marco del proceso asistencial conforme a sus convicciones personales.

Así las cosas, se concede el derecho a las personas con discapacidad de ejercer de forma autónoma sus derechos y no tener injerencia arbitraria de un tercero en caso de no ser deseado, pues el sistema de ayudas tampoco podrá intervenir autoritariamente en la plena capacidad y autonomía de las personas con discapacidad, por lo que el secreto médico y todas las garantías constitucionales y legales en el ámbito sanitario, como el consentimiento informado, solo podría verse revelados a él mismo, como titular de sus derechos, excluyendo a terceras personas, quienes solo podrán conocer acerca de la información develada al galeno con la 
respectiva autorización del paciente. Cabe resaltar que a nivel nacional no hemos logrado una manifestación idónea y suficiente de lo anterior, como consecuencia de un actuar omisivo y sosegado por parte del Estado y la sociedad.

De la prevalencia del secreto médico depende, en gran medida, la protección de un importante grupo de derechos fundamentales y derechos humanos que no pueden ser obviados por el Estado, y conforme a la condición de sujetos de especial protección que ostentan las personas con discapacidad, se les debe garantizar una vida plena, con el goce efectivo de sus derechos, entendiendo que lo preceptuado por el Comité de los Derechos de las Personas con Discapacidad y la comunidad internacional, en general, que sea ratificado por Colombia, debe ser implementado de forma adecuada dentro de nuestro ordenamiento jurídico, según el bloque de constitucional que pregona nuestra carta política.

\section{Conclusiones}

El secreto médico es una garantía de imperativo cumplimiento en nuestro contexto nacional, que vincula a todo galeno para su cumplimiento en favor del paciente, pues los derechos que dependen de su vigencia responden a una amplia lista que debe ser respetada y garantizada por el Estado y el galeno a todo ser humano, representados en la dignidad, la libertad, la autonomía, la confidencialidad y la privacidad, entre otros, que constituyen parte esencial de la persona, junto a la parte centrípeta del yo individual que ampara esta figura.

De igual forma, constituye una garantía polivalente, que representa un derecho fundamental-garantía constitucional-deber; dependiendo de la óptica observada (paciente o profesional de la salud). Posee como fin último la salvaguarda de toda información que llegara a conocer el galeno de su paciente en razón de su profesión, en aras de proteger la inescindible confianza y complicidad que se requiere para el idóneo ejercicio de las ciencias de la salud, sin la que el paciente no podría exteriorizar su intimidad y brindar la información verídica que requiera el galeno en la relación sanitaria. 
A pesar de ello, es un tema marginado por nuestra doctrina y legislación, siendo exigua la literatura relevante al respecto, y prácticamente inexistente su profundización y especificidad, obviando importantes características de esta garantía, aspecto que se agudiza en el caso de las personas con discapacidad, donde, por citada omisión, el galeno resulta acreedor de un amplio margen discrecional para decidir sobre la vigencia de esta figura, requiriéndose un rol proactivo de su parte para el cumplimiento de este derecho-deber, conforme a la tutela de derechos enunciados, principios bioéticos y el fuero interno de la persona con discapacidad.

Lo anterior sin una obligación legal previa y clara que le exhorte a actuar conforme a los deseos libres y autónomos del paciente, todo lo contrario, persisten de manera incólume instituciones y figuras jurídicas como el curador o representante legal que minusvaloran o minimizan el valor intrínseco de esta población, a pesar de los avances significativos desplegados a nivel internacional mediante la CDPD y el reconocimiento de plena capacidad jurídica, sistema de ayudas y demás, que permite actuar de manera digna y autónoma en todas las esferas de su vida, con miras a lograr la efectividad de sus derechos.

Por otra parte, observamos cómo es controvertida la posición de la CDPD sobre la no diferenciación entre los diferentes tipos de discapacidad, con especial énfasis en la cognitiva, fundándose en impedimentos naturales que sobreviene a esta última. En este ámbito, cabe resaltar que, a juicio del autor, ninguna de las posturas es lo suficientemente valedera, ya que si bien no es dable profundizar como fuere deseado, se recalca que evidentemente todo tipo de discapacidad posee unas necesidades y requisitos específicos que deben ser solventados con un sistema de ayudas adecuado y ajustado a las características del caso en concreto, pero es claro que un número reducido de discapacidades requieren ayudas de forma perentoria, que aunque deben respetar y salvaguardar la autonomía del individuo, no pueden obviarse o dejarse a la total discrecionalidad de este último, me refiero a estadios avanzados de discapacidad, como en la cognitiva aguda, síndrome de Asperger... donde el sistema de ayudas no puede ostentar un carácter facultativo, pero estos corresponden a casos excepcionalísimos en los que las barreras sociales se presentan como insoslayables; por lo tanto, declarar que "ningún" 
o "todo" tipo de discapacidad es totalmente autónomo constituye una generalización insostenible.

Por otro lado, respecto a los impedimentos naturales, es claro que estos no existen, las connotaciones negativas que se atribuyen a la discapacidad son consecuencia directa de la ferocidad social que impera en nuestro entorno, por lo que invito a reflexionar con la siguiente cita (Hanna, 2019);

Disability rights means (...) pursuing the career I want to pursue. (...) There is a lot of value in seeing someone with a disability doing something totally unrelated to their disability. And really, this is the point of disability rights: to let people do whatever they want to ... just like everybody else. (p. 2)

Se itera entonces, la necesidad de regular este derecho de forma adecuada y en miras a la prevalencia de los derechos de este grupo, delimitando satisfactoriamente el actuar debido por parte del galeno en la relación sanitaria, el paciente y la persona (dado el caso) que sea asignada mediante el sistema de ayudas, en la consecución de efectividad de los derechos en cabeza del paciente, como el secreto médico.

La relación galeno-paciente debe ser confidencial e íntima, y deben respetarse de manera cabal los deseos del paciente respecto a la conservación de la información develada, exceptuando casos excepcionales, pues la generalidad debe corresponder a una relación bilateral de respeto mutuo, sin interferencia arbitraria de terceros, donde no tendría validez suficiente la figura de tutor o representante legal, ni siquiera cuando se encuentre en desacuerdo con la decisión tomada por el paciente, pues esta última será la única determinante para el galeno respecto a su actuar en el devenir profesional.

Por último, nos encontramos en un panorama incierto, que a priori permite un amplio número de interpretaciones y aplicaciones, y aunque de un estudio minucioso y atento se evidencia la validez actual de esta figura en toda persona, se requiere una intervención estatal y social efectiva para modificar nuestra legislación, doctrina y concepción social que no dé lugar a dudas sobre las personas con discapacidad y sus derechos, para garantizar su eficaz prevalencia y salvaguarda. 


\section{Referencias}

Ablanedo Suárez, J. (2015). Ética, confidencialidad y enfermería. Mi historia ¿La historia de todos? RqR Enfermería Comunitaria, 3(3), 54-62.

Antomás Osés, J. \& Huarte del Barrio, S. (2011). Confidencialidad e historia clínica: Consideraciones ético-legales. Anales del Sistema Sanitario de Navarra, 34(1), 73-82.

Barbero Gutiérrez, J., Sánchez Caballero, M. \& Martín Cortecero, J. (2013). Secreto profesional y riesgo vital para un tercero identificado: metodología de análisis ético en torno a un caso. Revista de la Asociación Española de Neuropsiquiatria, 33(119), 555-573.

Bariffi, F. (2009). Capacidad jurídica y capacidad de obrar de las personas con discapacidad a la luz de la Convención de la ONU. En L. Perez Bueno, Hacia un Derecho de la Discapacidad. Estudios en homenaje al Profesor Rafael de Lorenzo (pp. 353-390). Pamplona: Thomson Reuters Aranzadi.

Bauman, D. (2004). Designing Deaf Babies and the Questions of Disability. Journal of Dead Studies and Dead Education, 10(3), 311-315.

Beauchamp, T., \& Childress, J. (1999). Principios de ética biomédica. Barcelona: Masson.

Benavides López, Á. (2015). Capacidad Jurídica: Una reflexión necesaria a la luz de la Convención sobre los Derechos de las Personas con Discapacidad. Anuario de Derechos Humanos, (11), 39-56.

Cifuentes Muñoz, Carlos, C- 264 (Corte Constitucional 13 de Junio de 1996). Cifuentes Muñoz, Eduardo, C-264 (Corte Constitucional 13 de Junio de 1996). Comité de Naciones Unidas sobre las Personas con Discapacidad, C. (2014). Observación General No. 1. ONU.

Córdoba Palacio, R. (1990). El secreto profesional médico. Medicina U.P.B., 9(1), 13-27.

De Asís, R. (2009). Sobre la capacidad. Papeles El tiempo de los Derechos.

De La Cruz Florez vs. Perú, Sentencia de Fondo, Reparaciones y Costas (Corte Interamericana de Derechos Humanos 18 de Noviembre de 2004).

De las Heras García, M. (2005). Estatuto ético-jurídico de la profesión médica. Madrid: Dykinson.

Decreto Legislativo No. 1384. (4 de Septiembre de 2018). Lima, Perú: Presidente de la República.

Fajardo Sandoval, F. (2013). El secreto profesional médico. Entre la práctica y los derechos humanos del paciente (Vol. II). Popayán: Samava Ediciones. 
Fernández Carlier. Rad. 33837 (Corte Suprema de Justicia. Sala Penal 18 de Marzo de 2015).

Fernández Muñoz, M. (2015). La Protección Del Paciente Frente a los Deberes de Información y Secreto Profesional Médico. Prolegómenos. Derechos y Valores, 18(35), 153-168.

Fernández, M. (2010). La discapacidad mental o psicosocial y la convención sobre los Derechos de las Personas con Discapacidad. Revista DFensor, (11), 10-17. Gaviria Diaz, Carlos, C - 411 (Corte Constitucional 28 de Septiembre de 1993). Hanna, J. (29 de Enero de 2019). Harvar Law Today. Recuperado de https:// today.law.harvard.edu/the-sky-is-not-the-limit/

Hernández, G. (2013). El secreto profesional en psicología: enfoque constitucional, legal y jurisprudencial en Colombia. Cuadernos Hispanoamericanos de Psicología, 13(2), 105-116.

Iglesias Díez, A. (2017). La mala educación: La violación sistemática del secreto médico en Argentina. Revista de Bioética y Derecho, (41), 85-105.

Jiménez Sandoval, R. (2008). Derecho y Discapacidad. San José: UNA.

Kant, I. (1999). Fundamentación de la metafísica de las costumbres. Barcelona: Ariel. Monereo Atienza, C. (2009). La complejidad social de la discapacidad. Algunos ejemplos de la narración fílmica. Cuadernos Electrónicos de Filosofía del Derecho, (19), 44-61.

Monserrat Pereña, V. (2010). La convención de Naciones Unidas y la nueva visión de la capacidad Jurídica. Revista del Instituto de Ciencias Jurídicas de Puebla, IV(26), 69-78.

OHCHR, C. s. (2014). Observación General No. 1. UN.

Organización Mundial de la Salud (OMS). (2003). Aborto Sin Riesgos: Guía Técnica $y$ de Políticas para Sistemas de Salud. Ginebra.

Organización Mundial de la Salud (OMS) \& Organización Panamericana de la Salud (OPS). (2001). Clasificación Internacional del Funcionamiento, de la Discapacidad y la Salud. Madrid. INMERSO.

Ortiz Delgado, Gloria, C-182 (Corte Constitucional 13 de Abril de 2016).

Peña-Salazar, C., Arrufat Nebot, F., Fontanet, A., García León, N., Más, S., Roura Poch, P. E Santos López, J. (2017). El infradiagnóstico del trastorno mental en la población con discapacidad intelectual: Estudio de prevalencia en población con diferentes grados de discapacidad intelectual. Siglo Cero, 48(3), 27-39.

Portilla Parra, S. (2019). Implicaciones jurídicas del método de edición genética CRISPR-Cas9, y su aplicación en personas con discapacidad. Papeles el tiempo de los derechos, (9), 1-22. Recuperado de https://redtiempodelosderechos. files.wordpress.com/2019/01/implicaciones-edicion-genetica-9-19.pdf 
Pretelt Chaljub, Ignacio, C-200 (Corte Constitucional 14 de Marzo de 2012).

Quinn, G. E Degener, T. (2002). Derechos Humanos y Discapacidad. Uso actual de posibilidades futuras de los instrumentos de derechos humanos de las personas con dispacidad. Nueva York, Ginebra: Naciones Unidas.

Ramírez Ortegón, L. (2009). Confidencialidad: normativas y consideraciones generales sobre su aplicación en Colombia. Revista Colombiana de Psiquiatría, 38(1), 177-184.

Ramos Montes, J. E Gabaldón Fraile, S. (2012). La confidencialidad en el ámbito de la discapacidad intelectual y la enfermedad mental. Revista bioética $\varepsilon$ debat, 18(67), 8-13.

Rendtorff, J. (2002). Basic ethical principles in European bioethics and biolaw: autonomy, dignity, integrity and vulnerability--towards a foundation of bioethics and biolaw. Medicine Health Care Philosophy, 5(3), 235-244.

Romeo Casabona, C. M. (2011). El Médico y el Derecho Penal. Los problemas actuales de la biomedicina, tendencias actuales de la legislación y jurisprudencia argentinas. Buenos Aires: Rubinzal Culzoni Editores.

Solé, J. (2016). Artículo 12 de la Convención. Hacía el fin de las tutelas. En F. V. Lucas, La incapacitación, reflexiones sobre la posición de Naciones Unidas (pp. 63-76). Barcelona, España: Cuadernos de la Fundación Victor Grífols i Lucas.

UN. (13 de Diciembre de 2006). Convención para los Derechos de las Personas con Discapacidad, artículo 12. Nueva York.

UN Human Rights Comittee, f. o. (1999). U.N.Doc.CCPR/C/79/Add.104. Santiado de Chile: ONU.

Valdés, E. (2011). El principio de autonomía en la doctrina del bioderecho. La lámpara de Diógenes, revista de filosofia, (22 y 23), 113-128.

Vargas Hernández, Clara, T-708 (Corte Constitucional 14 de Julio de 2008).

Ximenes Lopez vs Brasil, Fondo (Corte Interamericana de Derechos Humanos 4 de Julio de 2006). 